\title{
Current Treatment of Hydatid Liver Disease: Surgical Perspective
}

\author{
Abdul-Wahed Nasir Meshikhes* \\ Department of Surgery, Alzahra General Hospital, Qatif, Saudi Arabia
}

Submission: June 12, 2019; Published: June 21, 2019

*Corresponding author: Abdul-Wahed Nasir Meshikhes, MB ChB, FRCSI, FACS, Consultant Surgeon, Department of Surgery, Alzahra General Hospital, King Faisal Street, Qatif 31911, Eastern Province, Saudi Arabia

\begin{abstract}
Hydatid liver disease is endemic in certain parts of the world. However, easy travel and greater population mobility, make encountering this disease more likely in any part of the world. Although, majority of cases are asymptomatic, symptoms may develop as a result of pressure or complications such as rupture or infection with abscess formation. The diagnosis is made by history, blood tests including serological tests and imaging studies especially CT scan. Treatment can be either medical with anti-helminthic chemotherapy, percutaneous aspiration irrigation and re-aspiration under radiological guidance or surgery (either conventional or laparoscopic intervention). This mini-review summarizes the treatment of hydatid liver disease from surgical perspective.
\end{abstract}

Keywords: Liver hydatid; Echinococcus; Serology; Albendazole; Surgery; Laparoscopy; Scolicidal agent; Parasitic infection; Peritoneal cavity; Abdominal pain; Obstructive jaundice; Biliary tract; Biliary colic; Jaundice; Cholangitis; Pancreatitis

Abbreviations: ELISA: Enzyme-Linked Immunosorbent Assay; PAIR: Percutaneous Aspiration Injection Reaspiration; OC: Intra-Operative Cholangiogram; ERC: Endoscopic Retrograde Cholangiography

\section{Introduction}

Hydatid disease is a parasitic infestation by a tapeworm of the genus Echinococcus. It is endemic in certain parts of the world especially some Mediterranean countries, the Middle East, South America, Australia and New Zealand [1]. Greater population mobility and easy travel make encounter with this disease nowadays more likely worldwide. Hence, clinicians need to be fully aware of hydatid liver disease clinical presentation, diagnosis, and various methods of management especially the surgical treatment options. This mini-review highlights salient points in the treatment of hydatid liver disease from surgical perspective.

\section{Clinical Presentation}

Parasitic infection with Echinococcus Granulosus occurs after ingestion of contaminated food and water or after living or visiting an endemic area. Although hydatid may affect any organ, the liver is the most common organ to be infested [2]. Majority of hepatic hydatid cysts remain asymptomatic and only discovered incidentally. Symptoms develop as a result of pressure or mass effect of the enlarging cyst or due to cyst complications [2]. The mass effect produces abdominal pain and obstructive jaundice. Cyst may rup ture -either spontaneously or following abdominal trauma- into the biliary tract producing biliary colic, jaundice, cholangitis, and pancreatitis [3]. The cyst may become infected with subsequent abscess formation, or may also leak into the peritoneal cavity giving rise to increasing abdominal pain, and allergic reaction with flushing and urticarial [4]. Sudden spontaneous cyst rupture into the peritoneal cavity or the chest leads to anaphylactic reaction which may lead to death if not treated abruptly [5].

\section{Diagnosis}

Routine blood tests in patients with hepatic hydatid cyst are usually nonspecific, but liver function test may be disturbed with an elevated bilirubin and alkaline phosphatase. In cases of cyst infection, leukocytosis and eosinophilia may also occur. The results of Echinococcus serology are variable depending on the type of test performed. The indirect hemagglutination test and the enzyme-linked immunosorbent assay (ELISA) are very sensitive and can be utilized as the initial screening tests $[6,7]$. Immunodiffusion and immunoelectrophoresis tests provide specific confirmation of reactivity. The ELISA test is useful in the follow-up to detect recurrence [6,7]. 
The imaging studies are of great help in making accurate diagnosis. A plain abdominal film may reveal a rim of calcification or even a calcified hydatid cyst. Ultrasonography is helpful in diagnosing hydatid cyst when daughter cysts are visualized, but it is operator-dependent. Computerized tomography scan is very accurate in diagnosing hydatid liver disease and differentiating it from other benign liver cysts such as amoebic and pyogenic cysts [8].

\section{Treatment}

Treatment of hydatid liver cyst varies from medical chemotherapy to percutaneous drainage under radiological guidance, to surgical (either open or laparoscopic) intervention.

\section{Medical Treatment}

Medical therapy is indicated in patients with cysts that are inoperable due to either difficult cyst location or patient unfitness to surgery. The most commonly used chemotherapeutic agent is albendazole as it is associated with less side-effect than mebendazole. It is administered orally at $10-15 \mathrm{mg} / \mathrm{Kg}$ per day in 2 divided doses for 4 weeks followed by 14-day drug-free interval [9]. The cycle is repeated over 3-6 months. A combination therapy with weekly use of praziquantel has also been recommended in cases with intraoperative spillage [10].

Albendazole is contraindicated in early pregnancy and in patients with chronic liver disease or bone marrow suppression. It is also ineffective in cases of infected or calcified cysts. Complete blood count and liver function tests need to be monitored while on treatment especially in the first 3 months as it causes marrow suppression. The use of albandazole as a primary treatment of hydatid cyst may show decrease in size in about $50 \%$ of patients [2]. Treatment with albendazole therapy as adjunct to percutaneous drainage and surgery have been gaining acceptance in treatment of hydatid cystic disease. However, it was found ineffective in the vast majority of medically-treated patients; the overall success rate was only $8 \%$. Hence, it should not be used as the primary therapy for patients who are surgical candidates [11].

\section{Percutaneous Aspiration Injection Reaspiration (PAIR)}

The Percutaneous Aspiration Injection Reaspiration (PAIR) technique is performed in the interventional radiology suite using ultrasound or CT guidance. It involves aspiration of the cyst contents via a special cannula, followed by injection of a scolicidal agent (such as 20\% hypertonic saline solution, cetrimide or alcohol) for at least 15 minutes, and then reaspiration of the cyst contents $[12,13]$. This is repeated several times until the return fluid is clear. The cyst is then filled with isotonic sodium chloride solution. Perioperative treatment with albendazole is essential one week prior to the procedure and continued for 1-3 months after.

PAIR is indicated in cysts equal to or larger than $5 \mathrm{~cm}$ in diameter, multiple cysts, infected cysts, post-surgery recurrent cysts, surgically-inaccessible cysts and in patients who are unfit for surgery or pregnant patients. In this procedure, risk of spillage and anaphylaxis may occur especially in superficially located cysts, and hence, transhepatic puncture is recommended. Chemical sclerosing cholangitis may also occur in cases of biliary communication [14]. The procedure is now widely adopted and proved to be safe, efficacious and attractive treatment option. It is also cost-effective and associated with shorter hospital stay when compared to surgery. A recent systematic review and metaanalysis comparing PAIR to laparoscopic procedures in hydatid liver disease showed promising advantage of PAIR procedures over laparoscopic treatment. PAIR procedures have higher cure rate and lower complication and mortality rates. However, it is associated with higher recurrence rate than laparoscopic procedures [15].

\section{Surgical Treatment}

Surgery remains the mainstay of treatment for hydatid liver disease as it offers the only hope for complete cure. It is indicated for large liver cysts with multiple daughter cysts especially if superficially located. Such cysts are at risk of rupture either spontaneously or traumatically. It is also indicated for infected cysts and cysts presenting with pressure effects on vital organs or structures. Most of these indications are now managed by PAIR instead of surgery. Surgery is contraindicated in pregnancy unless there is a risk of pending rupture, and in patients who are medically unfit for general anesthesia. For such patients, PAIR is an alternative option. Very small cysts are better treated medically and observed regularly but, dead and well-calcified cysts are better left alone [2].

The choice of surgical technique is determined by the size, location and accessibility of the cyst, as well as the experience of the treating surgeon. The surgical treatment can be either conservative or radical. In conservative surgery, cystectomy or simple tube drainage of infected cysts are acceptable surgical techniques. But, in radical surgery, total pericystectomy or partial liver resection may be offered. The radical surgery is associated with lower risk of recurrences, but higher risk of complications [16]. The complication rate of radical surgery can be reduced if liver resections are performed by experienced hepato-biliary surgeons. The advocates of the conservative approach argue the disease is benign and hence radical surgery in the form of liver resection is not justified. In a recent review of 57 published articles (914 patients with 1116 hydatid cysts), most common surgical procedure was cystectomy $(60 \%)$, followed by partial pericystectomy (15\%) and pericystectomy $(8 \%)$ and the rest (17\%) were liver segmentectomies [17].

\section{Essential surgical steps}

Regardless of the contemplated surgical procedure, basic vital steps should be implemented. This involves cyst isolation, protection of the surrounding organs and abdominal cavity using packs soaked with a scolicidal solution, aspiration of the cyst and sterilization by injecting the cyst with a scolicidal agent. The cyst is then opened or de-roofed and the germinal membrane and 
daughter cysts are carefully removed without any spillage. The cyst cavity is then irrigated thoroughly with scolicidal agent of choice and inspected for any biliary communications. This is suspected by presence of bile-stained cyst fluid and presence of bile stains in the gauze packs that are placed in the cyst cavity after evacuation of its contents. Any obvious sites of biliary communication within the cyst cavity should be under-run with sutures.

What to do with the resultant cavity is a matter of controversy. The cavity is either marsipulated, closed primarily with or without external tube drainage, or packed with an omentum (omentoplasty) $[18,19]$. In the author's opinion omentoplasty is reserved for partially calcified cysts. Nevertheless, a prospective randomized trial found omentoplasty to be associated with less complication rate than external drainage procedures [18].

An intra-operative cholangiogram (OC) with or without common bile duct exploration, or perioperative endoscopic retrograde cholangiography (ERC) may be conducted for any hepatic hydatid cyst that communicates with the biliary tree $[10,20]$. These communications usually become apparent after the removal of the germinal membrane. Under-running of all visible communications should be done prior to performance of an OC or ERC. The complete obliteration of the cavity can take up to one year [21].

In cases of concurrent pulmonary and hepatic hydatid disease, the two pathologies can be dealt with simultaneously under the same anaesthetic - if the patient is fit - via separate thoracotomy and right subcostal laparotomy incisions. A single right thoracoabdominal approach may also be used in few selected patients. However, staged procedure may be offered if the patient cannot tolerate a lengthily procedure or one of the cysts is symptomatic with a high risk of rupture [22,23].

\section{Laparoscopic surgery}

Recently, an increasing number of hydatid liver operations are performed using the laparoscopic approach; albeit in selected cases. The basic principles of hydatid conventional open surgery are followed even if the procedure is carried out laparoscopically $[24,25]$. Uncontrolled spillage during pneumoperitoneum is a major concern and methods to minimize and control spillage to avoid hydatidosis and recurrence are currently lacking. This fear of spillage is higher during laparoscopic approach for hydatid cyst than that during the open approach. This may call for restricting the laparoscopic surgical approach to selected cases only.

Currently, there are no randomized controlled trials comparing laparoscopic hydatid cyst surgery with conventional open procedures. However, the feasibility and safety of laparoscopic interventions has been has been confirmed by several studies [24-26], including a meta-analysis of 22 retrospective studies that found that the laparocopic approach is associated with low morbidity and in-hospital mortality ( $13 \%$ and $0.3 \%$, respectively). The conversion rate to laparotomy is $4 \%$, recurrence rate $1.6 \%$ and a mean length of hospital stay of $<5$ days [27]. The most common complication after laparoscopic hydatid cyst surgery is bile leakage (6.2\%), and postoperative recurrence (1.0\%).
Therefore, it is now confirmed that the laparoscopic surgical technique is feasible and safe in the management of hydatid liver disease. Moreover, it has acceptable mortality and morbidity for both conservative and radical resections in selected patients $[17,27]$. Laparoscopic approach is even recommended for the management of liver hydatid cysts that are complicated by cysto-biliary communication [28]. It is still recommended that laparoscopic treatment of hydatid liver cyst is reserved for selected cases and conducted by an experienced laparoscopic surgeon who is fully conversant with minimally invasive techniques $[29,30]$.

A systematic review and meta-analysis comparing laparoscopic vs. open surgery in the management of hydatid liver disease showed no added advantage of the latter over the former [31].

Nevertheless, laparoscopic procedures are significantly associated with shorter operative time, lower complication rate, shorter hospital stay and better osmosis [32].

\section{The Choice of Scolicidal Agents}

There are many scolicidal agents that have been used over the years for hydatid cyst sterilization. These include formalin, hypertonic saline, hydrogen peroxide, chlorhexidine, savlon, absolute alcohol, and cetrimide [33,34]. A variety of complications have been reported in the world literature with all scolicidal agents. The most feared complication is chemical sclerosing cholangitis $[14,35,36]$. The risk is even higher in the presence of communication with the biliary tree. In presence of biliary communication, filling the cyst cavity with $20 \%$ hypertonic saline solution or any other scolicidal agents may be dangerous, causing chemical peritonitis, sclerosing cholangitis similar to that reported after the use of more toxic scolicidal agents such as formalin and hydrogen peroxide [35]. A combination of $0.5 \%$ cetrimide and $0.05 \%$ chlorhexidine has similar liver function results and histopathological effects on bile ducts to that of normal saline solution. Hence, it appears to be safe to use in cases of cystobiliary communication [34].

\section{Follow-up}

As hydatid liver disease is well known for its high recurrence after surgery, Long-term follow up is needed for postoperative patients to adequately address recurrence rates. It must be emphasized that the residual cavity after surgical evacuation takes about one year to obliterate. This information should be conveyed to the patient, so he/she is not alarmed by presence of a sterile cyst in the liver on future radiological imaging for other reasons $[20]$. The ELISA test is useful in follow-up to detect recurrence $[6,7]$.

\section{Conclusion}

Hydatid liver disease is endemic in certain parts of the world posing a major health hazard. Medical chemotherapy is no longer used as a primary treatment but, it has an important role as an adjunct to surgery or percutaneous drainage. There are many scolicidal agents but, cetrimide seems to be the safest to use. Although surgery is considered the mainstay of treatment that 
provides a lasting cure, PAIR is emerging as an attractive minimally invasive alternative with expanding indications especially in high surgical risk patients, recurrent hydatid liver disease and surgically-inaccessible cysts. Recent evidence suggests that laparoscopic hydatid liver cyst surgery is expanding with proven feasibility, safety and efficacy. However, the well-established basic surgical principles employed in conventional open surgery should be adhered to in laparoscopic procedures to minimize the risk of spillage and hence, reducing recurrence rate.

\section{References}

1. Torgerson PR (2013) The emergence of echinococcosis in central Asia. Parasitology 140(13): 1667-1673.

2. Shaw JM, Bornman PC, Krige JE (2006) Hydatid disease of the liver. S Afr J Surg 44(2): 70-72.

3. Gupta P, Debi U, Sinha SK, Prasad KK (2015) Role of endoscopic retrograde cholangiography in ruptured hepatic hydatid cyst. Trop Gastroenterol 36(1): 21-24

4. Meshikhes AW (2013) An unusual cause of acute abdominal pain in a young man. BMJ Case Rep. BMJ Case Rep. doi:10.1136/ bcr-2013200285

5. Jedidi M, Mlayeh S, Masmoudi T, Souguir MK, Zemni M (2014) Sudden death due to hydatid cyst: thirty-four medicolegal autopsy cases. Am J Forensic Med Pathol 35(1): 29-33 BMJ Case Rep. doi:10.1136/ bcr2013-200285.

6. Liu D, Lightowlers MW, Rickard MD (1992) Evaluation of a monoclonal antibody-based competition ELISA for the diagnosis of human hydatidosis. Parasitology 104(Pt 2): 357-361.

7. Filippou D, Tselepis D, Filippou G, Papadopoulos V (2007) Advances in liver echinococcosis: diagnosis and treatment. Clin Gastroenterol Hepatol 5(2): 152-159.

8. Gupta P, Debi U, Sinha SK, Prasad KK (2015) Role of endoscopic retrograde cholangiography in ruptured hepatic hydatid cyst. Trop Gastroenterol 36(1): 21-24.

9. Meshikhes AW (2004) Surgical treatment of hydatid cysts of the liver Br J Surg 91(4): 510-511.

10. Nazligul Y, Kucukazman M, Akbulut S (2015) Role of chemotherapeutic agents in the management of cystic echinococcosis. Int Surg 100(1): 112-114.

11. Kapan S, Turhan AN, Kalayci MU, Alis H, Aygun E (2008) Albendazole is not effective for primary treatment of hepatic hydatid cysts. Gastrointest Surg 12(5): 867-871.

12. Akhan O, Akkaya S, Dağoğlu MG, Akpınar B, Erbahçeci A, et al. (2016) Percutaneous Treatment of Splenic Cystic Echinococcosis: Results of 12 Cases. Cardiovasc Intervent Radiol 39(3): 441-446.

13. Gomez I Gavara C, López-Andújar R, Belda Ibáñez T, Ramia Ángel JM, Moya Herraiz Á, et al. (2015) Review of the treatment of liver hydatid cysts. World J Gastroenterol 21(1): 124-131.

14. Polo JR, Garcia-Sabrido JL (1989) Sclerosing cholangitis associated with hydatid liver disease. Arch Surg 124(5): 637.

15. Sokouti M, Sadeghi R, Pashazadeh S, Abadi SEH, Sokouti M, et al. (2019) A systematic review and meta-analysis on the treatment of liver hydatid cyst using meta-MUMS tool: comparing PAIR and laparoscopic procedures. Arch Med Sci 15(2): 284-308.

16. Georgiou GK, Lianos GD, Lazaros A, Harissis HV, Mangano A, et al. (2015) Surgical management of hydatid liver disease. Int J Surg 20: 118-122.
17. Tuxun T, Zhang JH, Zhao JM, Tai QW, Abudurexti M, et al. (2014) World review of laparoscopic treatment of liver cystic echinococcosis--914 patients. Int J Infect Dis 24: 43-50.

18. Wani AA, Rashid A, Laharwal AR, Kakroo SM, Abbas M, et al. (2013) External tube drainage or omentoplasty in the management of residual hepatic hydatid cyst cavity: a prospective randomized controlled study. Ger Med Sci 11: 11.

19. Losanoff JE, Richman BW, Jones JW (2004) Organ-sparing surgical treatment of giant hepatic hydatid cysts. Am J Surg 187(2): 288-290.

20. Galati G, Sterpetti AV, Caputo M, Adduci M, Lucandri G, et al. (2006) Endoscopic retrograde cholangiography for intrabiliary rupture of hydatid cyst. Am J Surg 191(2): 206-210.

21. Ertem M (2001) False recurrence of laproscopically treated hydatid cysts. Surgery 129(3): 383.

22. Geraci G, Sciuto A, Lo Nigro C, Sciumè C, Li Volsi F, et al. (2012) Bilateral lung and liver hydatid cysts. Case report. G Chir 33(6-7): 229-233.

23. Parvizi R, Namdar H, Bilehjani E, Bayat A, Sheikhalizadeh MA (2013) Simultaneous operation of hydatid cyst of the heart and liver: a case report. J Cardiovasc Thorac Res 5(3): 127-128.

24. Ertem M, Uras C, Karahasanoglu T, Erguney S, Alemdaroglu K (1998) Laparoscopic approach to hepatic hydatid disease. Dig Surg 15(4): 333-336.

25. Khoury G, Jabbour-Khoury S, Bikhazi K (1996) Results of laparoscopic treatment of hydatid cysts of the liver. Surg Endosc 10(1): 57-59.

26. Chen W, Xusheng L (2007) Laparoscopic surgical techniques in patients with hepatic hydatid cyst. Am J Surg 194(2): 243-247.

27. Citgez B, Battal M, Cipe G, Karatepe O, Muslumanoglu M (2013) Feasibility and safety of laparoscopic hydatid surgery: a systematic review. Hepatogastroenterology 60(124): 784-788.

28. Chopra N, Gupta V, Rahul Kumar S, Joshi P, Gupta V, et al. (2018) Liver hydatid cyst with cystobiliary communication: Laparoscopic surgery remains an effective option. J Minim Access Surg 14(3): 230-235.

29. Vardakostas D, Damaskos C, Garmpis N, Antoniou EA, Kontzoglou K, et al. (2018) Minimally invasive management of hepatic cysts: indications and complications. Eur Rev Med Pharmacol Sci 22(5): 1387-1396.

30. Toro A, Schembari E, Mattone E, Di Carlo I (2018) Hydatid Cyst of the Liver: A Challenge that can be Amplified Shifting from Open to Laparoscopic Surgery. World J Surg 42(9): 3054-3055.

31. Sokouti M, Sadeghi R, Pashazadeh S, Abadi SEH, Sokouti M, et al. (2017) A systematic review and meta-analysis on the treatment of liver hydatid cyst: Comparing laparoscopic and open surgeries. Arab J Gastroenterol 18(3): 127-135.

32. Minaev SV, Gerasimenko IN, Kirgizov IV, Shamsiev AM, Bykov NI, et al. (2017) Laparoscopic Treatment in Children with Hydatid Cyst of the Liver. World J Surg 41(12): 3218-3223.

33. Besim H, Karayalçin K, Hamamci O, Güngör C, Korkmaz A (1998) Scolicidal agents in hydatid cyst surgery. HPB Surg 10(6): 347-351.

34. Aydin C, Kayaalp C, Nessar G, Zengin N, Balkan M, et al. (2014) Is cetrimide-chlorhexidine risky for secondary sclerosing cholangitis? Adv Clin Exp Med 23(3): 395-398.

35. Belghiti J, Benhamou JP, Houry S, Grenier P, Huguier M, et al. (1986) Caustic sclerosing cholangitis. A complication of the surgical treatment of hydatid disease of the liver. Arch Surg 121(10): 1162-1165.

36. Sathyanarayana MV, Shenoy MG, Pai VM, Haque PW, Hegde P, et al. (1996) Metabolic acidosis induced by cetrimide-chlorhexidine solution in hydatid cyst surgery. Indian J Gastroenterol 15(3): 104. 
This work is licensed under Creative Commons Attribution 4.0 License DOI: 10.19080/ARGH.2019.13.555861
Your next submission with JuniperPublishers will reach you the below assets

- Quality Editorial service

- Swift Peer Review

- Reprints availability

- E-prints Service

- Manuscript Podcast for convenient understanding

- Global attainment for your research

- Manuscript accessibility in different formats ( Pdf, E-pub, Full Text, audio)

- Unceasing customer service

Track the below URL for one-step submission https://juniperpublishers.com/online-submission.php 